\title{
Chapter 29 \\ Researching Ageism in Health-Care and Long Term Care
}

\author{
Sandra C. Buttigieg, Stefania Ilinca, José M. S. de Sao Jose, \\ and Annika Taghizadeh Larsson
}

\subsection{Introduction}

Even as the literature documenting the numerous negative consequences of ageism for the experiences of older people is constantly growing (Minichiello et al. 2000; Dionigi 2015; Chrisler et al. 2016), ageism remains an elusive concept, interchangeably used to cover a wide range of phenomena. Research on ageism across contexts reveals the equivocal manner in which it is defined. Existing definitions of ageism cover intolerant knowledge, values, attitudes and behaviors towards older people or more generally, people of a certain age. Commonly, ageism is distinguished from age discrimination, the latter often defined as only one of many possible manifestations of ageism, and used in the context of labor market research to describe the manifest preference for younger employees. It is important to recognize that there is a spectrum of concepts related to ageism depending more often than not on the context in which it is studied. In this chapter, we aim to provide an overview of how

\footnotetext{
S. C. Buttigieg $(\bowtie)$

Department of Health Services Management, Faculty of Health Sciences, University of Malta, Msida, Malta

e-mail: sandra.buttigieg@um.edu.mt

S. Ilinca

European Centre for Social Welfare Policy and Research, Vienna, Austria e-mail: ilinca@euro.centre.org

J. M. S. de Sao Jose

Faculty of Economics, University of Algarve, Faro, Portugal

e-mail: jsjose@ualg.pt
}

\author{
A. T. Larsson \\ Division Ageing and Social Change, Linkoping University, Norrkoping, Sweden \\ e-mail: annika.t.larsson@liu.se
}


ageism is defined, measured and assessed in research on healthcare and long-term care, and use some of the emerging research evidence for the existence of ageism in these two contexts in order to exemplify. Focusing on ageism (focusing, for the purpose of this chapter on its relation to old age) we aim to critically analyze the conceptualization and measurement/assessment of ageism in existing empirical literature covering the wide spectrum of care from emergency and acute care to chronic and long-term care of older adults in order to make recommendations for future research. In so doing, we aim to provide insights into the various theoretical/ conceptual and methodological approaches that researchers can employ for measuring and assessing ageism. As part of the Memorandum of Understanding for the implementation of a European Concerted Research Action, designated as 'COST Action IS1402: Ageism - a multi-national, interdisciplinary perspective', of which the authors form part, five methodological aspects related to ageism were selected as relevant. These are assessment; spatial design; prevalence, antecedents and consequences; intervention; conceptualization and theory.

In this chapter, we focus on two of the aforementioned aspects, namely 'assessment' and 'conceptualization and theory' and aim to answer the following questions:

(i). Why is it important to know how ageism in healthcare and long-term care has been empirically studied? (Sect. 29.1)

(ii). What evidence for the existence of ageism among key stakeholders (e.g. health care professionals and long-term care workers, family members and older adults) is reported in empirical research covering these two contexts? (Sect. 29.2)

(iii). Which are the conceptual and methodological approaches used to measure and assess ageism involving these key stakeholders in the two contexts? (Sects. 29.3 and 29.4)

\subsection{Why Is It Important to Know How Ageism in Healthcare and Long-Term Care Has Been Empirically Studied?}

Health and long-term care represent important settings in relation to old age and ageism as they cover the full pathway of delivery of care related to health and illness that older adults often need to access. As populations are ageing, in particular in developed countries, increasing numbers of older adults pass through the wide spectrum of care from emergency and acute care to chronic and long-term care on a daily basis. The spectrum of care includes community and public health, primary care, emergency medicine, acute care, care of chronic illness and long term care - both institutionalized, as well as home/community-based. Health care and long-term care are complimentary yet diverse in the services offered, acuity of care, characteristics of health care professionals caring for older people, as well as in 
terms of proportion and age of older persons cared for. In particular, long-term care tends to have a higher percentage of vulnerable oldest old. Additionally, length of stay is longer in these settings, thereby potentially increasing the possibilities for discriminatory situations to arise. Furthermore, the level of education and training of care-workers in long-term settings may be very different from that of health care professionals in acute settings.

Our focus on ageism in health and long-term care is further motivated by huge gaps in the literature with regard to the real needs of care for this age group, a situation that may be interpreted as ageist and specifically deficient in focus when it comes to delivery of care for older people. This is most probably due to the fact that the younger age groups have more often than not attracted attention from health policy makers, as well as from hospital and primary care administrators and providers (Robb et al. 2003; American Diabetes Association 2015). Gatz and Pearson (1988) labeled the attitudes shown toward older adults, namely the specific treatment biases that are based on negative misconceptions, as a problem and defined it as "professional ageism." Specifically, Hunold et al. (2016) remarked that emergency departments (ED) are progressively becoming a critical site of care for older adults, but there is still minimal knowledge regarding the priorities of care delivery for this population. The same authors identified accuracy and efficiency of the medical evaluation as the most common but lacking priorities among older adults in the ED. Similarly, Aminzadeh and Dalziel (2002) argued that the currently practiced disease-oriented and discontinuous models of emergency care are not sufficient to match the multidimensional needs of frail older patients, who have divergent patterns in terms of care needs, as well as service use (Scott et al. 2007). This situation calls for further research to assess the effectiveness of triage and intervention strategies pursuing vulnerable older ED patients. With regard to acute care, particularly inpatient services, the major users are older people - a contribution of the ageing population but also a reflection of the evolving patterns of disease, i.e. chronic with acute complications, multiple comorbidities and functional consequences (Koch et al. 2009). Indeed, most health care systems are adapting to this change in users/patients age groups by redesigning and shifting care for younger adults to the community, primary care and day care where possible (Koch et al. 2009). However, one still questions the persistently reported fragmented care of older adults and urgently calls for an older patient priority-directed and holistic decision-making process that addresses the needs of older adults with multiple chronic conditions (Tinetti et al. 2016).

Fried and Ferrucci (2016) highlight the fact that the contribution of aging to chronic diseases can no longer be toned down. Geriatricians and gerontologists have approached this problem through the conceptualization of frailty as a diagnosable clinical syndrome characterized by marked susceptibility to stress, underlying loss of resiliency and diminished functional reserve. In health services, which cater for the care of chronic diseases, as well as in long-term settings, there is the tendency for professionals who may have internalized ageist attitudes during their formative years to use patronizing talk to older people, which Nelson (2005) considers as self-fulfilling prophecies that can translate ageist stereotypes into actual behavior and eventually into lower levels of older persons' empowerment of their care. 
Furthermore, Coleman (2003) and Boockvar et al. (2004) identify transitioning of care from health to long-term care facilities as commonplace for older adults, who are often somewhat 'lost' or 'sidelined' in terms of clinicians' priorities particularly when long lengths of stay in acute settings are mainly due to lack of space in long-term institutions. Indeed, older patients in acute settings are often considered a burden on the health system and are labelled as 'social cases' (Cohen et al. 2014) or 'bed-blockers' (Hawkes 2016). Perhaps more distressing is that at the far end of the spectrum of care, Condelius and Andersson (2015) state that there are gaps in the literature as to what care older people access throughout the last stages of their life, as well as which factors enable access to care in this group.

Statistics from the United Nations predict that by 2030, older persons are expected to account for more than $25 \%$ of the populations in Europe and in Northern America, 20\% in Oceania, 17\% in Asia and in Latin America and the Caribbean, and 6\% in Africa (United Nations World Populations Ageing 2015). Therefore, it is more likely that in the foreseeable future, the need for services in health and longterm care will continue to increase as will the risk that older people are not looked upon and treated as full citizens in these settings.

From such accounts it becomes evident that a structured analysis of ageism in health and long-term care is both timely and pertinent. However, without a comprehensive conceptualization and operationalization of ageism efforts to measure and assess the multiple manifestations of ageism in these two contexts are bound to fail. Consequently, we are not able to fully tackle ageism in practice. It is therefore important to evaluate the state of empirical research concerning ageism in both health and long-term care in terms of, identifying the definitions used, and the conceptual and methodological approaches applied. Only by so doing can we uncover the strengths and weaknesses of research in this field and help guide future research efforts towards the areas most in need of being addressed.

Finally, we hope that our results can contribute to the development of what we consider that acceptable quality of care for older adults should embrace; that is, the holistic bio-psychosocial model delivered by interdisciplinary teams of health care professionals, who are competent in the care of older people and that steers away from fragmented, chaotic and ageist delivery of care. This model of care is becoming even more relevant in view of emerging evidence that the integration of attitudes, values, standards and opinions referred to as internalization of ageist stereotypes is related to memory failures, physical frailty and risk of cardiovascular events (Levy 2009).

\subsection{Evidence for the Existence of Ageism in Health and Long-Term Care}

This section is organized in two subsections, one focused on health care and the other one on long-term care. In both sections we consider the evidence in relation to three groups of research participants, namely care professionals, family members and 
older people. In providing an overview of the evidence of ageism and ageist practices in health and long-term care, we consider each sector separately. Our choice reflects the clear separation in the specialized literature between analyses in health or in longterm care settings, with virtually no overlap or joint consideration in extant studies. It is also important to draw attention to the fact that each subsection considers evidence of ageism in relation to three stakeholder groups, namely health and long-term care professionals, family members and older people. This stands in recognition of their separate but equally important roles in the process of care.

\subsection{Ageism in Health Care}

Existing empirical research on ageism in health care mainly involves health care professionals across different disciplines (São José et al. 2017). Examples include doctors in primary health care, where ageism is related to clinical decision-making (Adams et al. 2006; Arber et al. 2006), physicians in hospital in their recommendations for physical activity among individuals with arthritis (Austin et al. 2013), unfair judging by Florida physicians of older adults simply because of their advanced age (Gunderson et al. 2005). Other examples are physicians deciding on access to critical care that is influenced by age against older people (Hubbard et al. 2003), and significant differences in access to treatment, depending on the patients' chronological age and prescribing chemotherapy less frequently as the patients' chronological age increase (Protiere et al. 2010).

There are also studies focusing on ageism in research in health care, involving researchers in diabetes. Here, evidence of ageism is related to "the extent of exclusion of older individuals from ongoing clinical trials regarding type 2 diabetes mellitus" (Cruz-Jentoft et al. 2013; p. 734) and "(...)"whether exclusion of older people was prevalent in research proposals submitted to Dublin teaching hospitals" (Briggs et al. 2012, p.311).

Another group of health professionals involved in the body of research on ageism in healthcare is nurses, such as nurses caring for individuals with spinal cord injury (Furlan et al. 2009, p. 674). In one of these studies (Gething et al. 2002), evidence of ageism is related to patterns of stereotyping among nurses in Australia and the United Kingdom. Furthermore, Kydd et al. (2014) described attitudes of nurses and nursing students in Scotland, Sweden and the US towards working with older people. Moreover, Holroyd et al. (2009) reported that negative biases and ageist attitudes among caregivers, and particularly nurses, toward older people in acute care settings, are among the more notable expressions in the health care system.

Some studies report on evidence of ageism in distinct areas of specialization, namely psychiatry (Bouman and Arcelus 2001) in the sense of taking a sexual history far more frequently of middle-aged men and of neglecting to do so in older male patients, and oncology (Kearney et al. 2000), whereby healthcare professionals (physicians, nurses and radiographers) may discriminate against older people. 
There are also studies that provide evidence of ageism involving older adults themselves. Chambaere et al. (2012) reported that the level of involvement of patients in decision making to intensify pain alleviation decreases with increasing age. Additionally, Koch and Webb (1996) described the 'conveyor belt' way of organizing care in wards, whereby patients dominated by the demands of the work timetable, powerless to have any influence on their own care and unable to express their individual needs. These authors also reported segregation in that providers label older adults as "old". Furthermore, Makris et al. (2015) reported that ageism emerged as a result of dismissing or minimizing comments by providers that can serve to inform or reinforce older adults' beliefs that back pain is directly related to old age, or perhaps, that providers have nothing more to offer.

\subsection{Ageism in Long-Term Care}

Existing empirical research on ageism in long-term care contrasts with that in healthcare in that the studies more often involved older adults and family members and less frequently care professionals as participants. This may be due to the fact that the subjects are more easily accessible in long-term care.

Most studies on ageism in long-term care involve residents in long-term institutions (Ayalon 2015; Bodner et al. 2011; Dobbs et al. 2008; Doyle 2014; Gamliel 2000; Lagace et al. 2011, 2012; Macdonald and Butler 2007; Roth et al. 2012, 2015; Taverna et al. 2014; Zimmerman et al. 2014). Ayalon (2015) reported a prominent general view of old age as a sign of decline and decay. This negative view of old age was stated as prominent among adult children, as well as their older parents. Zimmerman et al. (2014) also report evidence of ageism, namely physical environment (environmental press [ex.: not repairing a bathroom nearby because of budget restrictions]; not using social space for engagement [ex.: sticking all the older people in the front and leave them there]); using labels to describe different types of residents; multi-level settings (not minimizing "us" versus "them" [ex.: older people who are relatively autonomous and older people who are dependent]); independence (not supporting autonomy [e.g.: discouraging older people from doing certain tasks]); respect (not valuing the resident [ex.: feeling like a prisoner]); privacy (not providing privacy); care provision (not taking the focus off of decline [e.g.: reinforcing dependence and decay]; constant supervision).

Several studies on ageism in long-term care involved health care professionals, care workers and administrators of long-term institutions (Band-Winterstein 2015; Billings 2006; Dobbs et al. 2008; Dunworth and Kirwan 2012; Lagace et al. 2011; Reyna et al. 2007; Roth et al. 2012, 2015; Taverna et al. 2014; Wells et al. 2004; Zimmerman et al. 2014). For example, Band-Winterstein (2015) reported ageism as neglect in the everyday routine of care with the following emerging themes (being transparent; being invisible; being forgotten; perceiving older patients as no longer human; being treated as an object, in an automated fashion; lack of accurate medical diagnosis; using ageist language; using less expensive materials on older patients, 
because money is not wisely spent on older persons; older persons lose their sexuality, which justifies mixed communal and social participation of older people); and avoidance (attitudes and behaviour regarding social contact with older people). Billings (2006) reported evidence of ageism in professionals from health care and social care in terms of insensitive treatment in relation to communication and attitude; excluding older people from conversations, sensitive or otherwise; shouting at older people; being patronising; little assessment of the preferred way that older people like to be addressed; not giving an older person enough privacy when helping them with activities such as toileting, washing or dressing; letting older people have a limited choice in things such as when and what they eat, when they go to bed or have a bath; older people are given too many tablets which are not reviewed often enough; and that there are assumptions that older people are not sexually active.

There are also a few studies in this body of research that involved family members as subjects (Ayalon 2015; Condelius and Andersson 2015; Dobbs et al. 2008; Roth et al. 2012, 2015; Zimmerman et al. 2014). In particular, Condelius and Andersson (2015) reported ageism among the next of kin, "in that they perceive some conditions and complaints as a natural part of ageing with further examinations or treatments being regarded as "pointless" or even "wasted" (p. 11).

To sum up, existing empirical research in the contexts of health and long-term care provides an interesting continuum and diversity in terms of the evidence of ageism provided and the stakeholder groups that are surveyed.

\subsection{Theoretical and Conceptual Approaches in the Study of Ageism}

On an overall level, what appear as most striking in relation to theoretical and conceptual approaches in the empirical study of ageism in health and long-term care is that most studies in both of these areas do not, at least explicitly, apply any theory, and that very few studies use theories of ageism. Thus, the literature on ageism in health and long-term care appears as under-theorized. Particularly striking is the relative absence of theories of ageism. While the vast majority of the literature is occupied with studying the causes, the consequences and possible preventive strategies of ageism, scant attention has been paid to its conceptualization (Iversen et al. 2009). As many, non-harmonized definitions coexist in the field, the formulation of a general theory on the causes and effects of ageism, which can help ground empirical research in a coherent fashion, is rendered impossible (Iversen et al. 2009). In fact, our survey of the empirical literature on ageism in health and long-term care yielded a majority of studies that altogether lack any references to a theoretical framework and that are underpinned by definitions and conceptualizations of ageism, often only implicitly defined.

Interestingly, even when established theoretical frameworks are included, they are rarely theories specifically focused on ageism of ageism. The literature on ageism 
in health care is affected by the disconnect between empirical work and theoretical thinking on ageism. While a minority of studies is grounded in the conceptual works of Butler (1969), Butler and Lewis (1973), Bytheway and Johnson (2001), Levy et al. (2006), the vast majority fail to mention any theoretical framework or to interpret their results within a broader theoretical context. Other theoretical frameworks not specific to ageism, but employed in selected studies on ageism in health care include psychological models of clinical decision-making, the Behavioral Model of Health Services Utilization, The social ecological perspective (Moos 1979; Stokols 1992; Parke \& Chappell, 2010) and Allport's intergroup contact theory (Ajzen 2005). Theories that are normally used to study/discuss ageism in long-term care (São José et al. 2017) are as diverse as Goffman's perspectives on stigma and depersonalization in institutions are applied, Age Stratification Theories, Foucault's perspectives on power, and Normative Ethical Theories are employed by authors, while Terror Management Theory (Solomon et al. 1991) or Social Identity Theory (Turner and Reynolds 2010), that explicitly refers to the concept and phenomenon of ageism, if at all mentioned, are relegated to the discussion sections.

To date, the most comprehensive conceptualization attempt for ageism is offered by Iversen et al. (2009) in their seminal paper on the conceptual analysis of ageism. Starting from an in-depth review of existing definitions and theoretical works, they structured the core aspects of ageism along four dimensions and proposed and enriched, multi-dimensional conceptualization: "Ageism is defined as negative or positive stereotypes, prejudice and/or discrimination against (or to the advantage of) older people on the basis of their chronological age or on the basis of a perception of them as being 'old' or 'elderly'. Ageism can be implicit or explicit and can be expressed on a micro-, meso- or macro-level".

As identified by the authors, the key dimensions in the ageism concept are the three classical components (cognitive-stereotypes, affective-prejudice, behaviouraldiscrimination); the positive/negative aspect (positive ageism, negative ageism), the conscious/unconscious aspect (explicit ageism, implicit ageism); and the levels at which ageism can manifest (micro-level ageism, meso-level ageism, macro-level ageism) (Iversen et al. 2009). To these dimensions, Sao Jose and Amado (2017) add the self-directed/other-directed aspect of ageism, manifesting exclusively at the micro-level, in recognition of the prevalence of negative stereotypes towards people of one's own age or towards oneself, a phenomenon aptly described by Bodner et al. (2011) as 'self-ageism'.

Mapping existing empirical literature on ageism in health and long term-care over the main components of ageism, a spectrum of 32 possible variants of ageism emerges at their intersection (see Table 29.1). Not surprisingly, no studies in the empirical literature on ageism in health and long-term care recognize and account for the complexity of the ageism concept along all five dimensions (see Table 29.1 for a visual depiction of the different variants of ageism and an overlayed mapping of the empirical literature on ageism in the two settings). In fact, as numerous contributions rely on Butler's classical definition of ageism (1975) they recognize only five of the 32 components, namely: cognitive, behavioural, other-directed, explicit and negative ageism. Even more recent definitions of ageism that have been 
Table 29.1 Variants of ageism and literature mapping

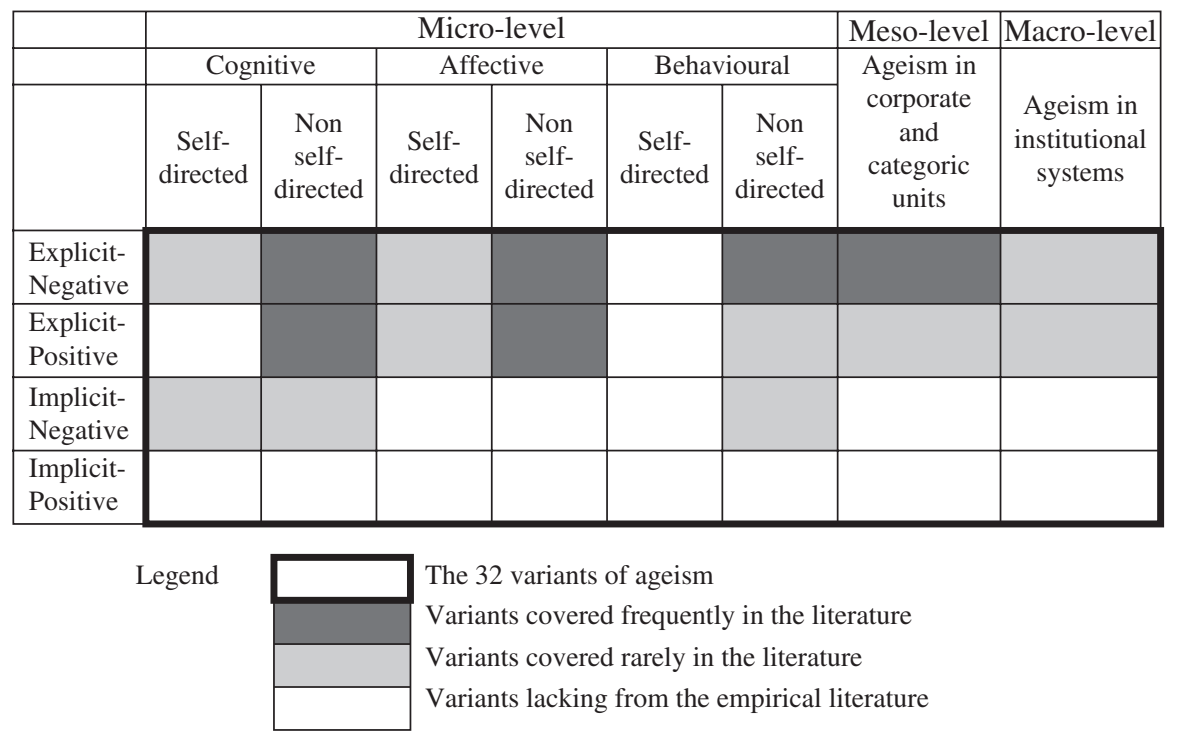

Source: Adapted from Iverson et al. (2009) and Sao Jose and Amado (2017)

employed in the empirical literature, as those proposed by Cuddy et al. (2005), Greenberg et al. (2002), Levy and Banaji (2002) and others, while generally more comprehensive in their scope, cover at most 10 components.

\subsection{Comparison of Research on Ageism in Health and Long-Term Care}

Concerning differences between the empirical literature on ageism in health and long-term care, among the three classical components of ageism, discrimination against people of a certain age, that is the behavioral components, is by a large margin most represented in the empirical literature on ageism in health care. The majority of studies concern themselves with identifying forms of discrimination in diagnosis (Adams et al. 2006, Arber et al. 2006, Rudd et al. 2007, Bond et al. 2003), discrimination in treatment and management (Koch and Webb 1996; Chambaere et al. 2012; Pedersen and Mehlsen 2011; Grant et al. 2000; Gnavi et al. 2007; Austin et al. 2013), discrimination in access to research and clinical trials (Cruz-Jentoft et al. 2013; Briggs et al. 2012) and differences in survival rates (Peake et al. 2003; Grant et al. 2000). The cognitive component, mainly addressed in qualitative studies, is generally reflected in research on the stereotypes and assumption about older patients not belonging in specific care institutions (Parke and Chappell 2010), about symptoms that are "normal" at more advanced ages (Iliffe et al. 2005; Makris et al. 2015) and about expected responses to treatment (Skirbekk and Nortvedt 2014). 
Finally, analyses of the affective component are all but absent in the literature on health care, with only one, recent study discussing prejudice towards older people, ageing and old age (Kydd et al. 2014) identified in our literature survey. The literature on ageism in long-term care, on the other hand, presents a more balanced division of interest between the three components. Negative stereotypes about the condition and abilities of older individuals (Band-Winterstein 2013; Billings 2006; Condelius and Andersson 2015) and about old age in general (Ayalon 2015; Gamliel 2000; Petersen and Warburton 2012; Roth et al. 2012) as well as negative reactions and prejudices towards older people (Dobbs et al. 2008; Roth et al. 2012; Natan et al. 2013; Wells et al. 2004) are well mapped in empirical studies. Finally, studies of discrimination against older adults in long-term care include such diverse topics as controlling the interaction and using inappropriate and diminishing language with older individuals (Band-Winterstein 2013; Lagacé et al. 2011; Doyle 2014), limiting older individuals' privacy (Billings 2006), providing sub-standard care (Band-Winterstein 2013; Doyle 2014) and segregating residents in long-term care facilities within age groups (Roth et al. 2012).

The representation of other ageism dimensions in the empirical literature is also highly skewed. We were able to identify only one study focusing on ageism in health care that explicitly considers positive stereotypes about ageing (Gunderson et al. 2005). Research on long term care more often recognizes the positive aspect of ageism (Lagacé et al. 2011; Natan et al. 2013; Wells et al. 2004) although it rarely takes a central place in the analysis. A noteworthy exception is the study of Taverna et al. (2014) who link the desire on the part of long-term care staff to respect residents' independence and autonomy due to their age (positive discrimination) to improper oral hygiene (a negative health outcome). This imbalance towards negative aspects of ageism is likely driven by a desire among researchers to identify those attitudes and behaviors that are likely to harm older individuals and lower the quality of the care they receive, in order to find ways to curtail them. However, the study of Taverna et al. (2014) is a case in point that all ageist attitudes and discrimination, even positive ones, can have negative effects, albeit unintended ones, and should therefore be considered in research more often.

Further differences between research on ageism in health and long-term care are that empirical studies on ageism in health care exclusively address the non self-directed aspect. This situation likely stems from the nature of interactions between older patients and their health care professionals, characterized by large information and control imbalances, shorter care spells and a focus on symptoms and disease. In long-term care, however, where older individuals interact both with caregivers and other residents for longer periods of time and with a more general goal of addressing both physical and psychological wellbeing of the care recipients, issues related to self-directed ageism are more salient. The empirical research on ageism in long-term care includes studies on ageist attitudes among older individuals themselves (Ayalon 2015) and discriminatory behaviors towards other older aged groups (Roth et al. 2012), as well as how these attitudes and behaviors are shaped by the specificities of the community or residential care environment (Gamliel 2000; Bodner et al. 2011). 
Concerning similarities between research on ageism in health and long term care, due to obvious difficulties in their systematic study, implicit stereotypes, prejudices and discrimination are rarely acknowledged in both bodies of the empirical literature and are addressed almost exclusively in qualitative studies. They address the existence of stereotypes and assumptions about older patients and residents that care professional hold, without being consciously aware of their presence or harboring any ill intention. Nonetheless, such attitudes can lead to improper care (Skirbekk and Nortvedt 2014) or delayed diagnosis, assessment (Pedersen and Mehlsen 2011) and treatment (Iliffe et al. 2005; Makris et al. 2015) with clear risks for negative health outcomes. Research on ageism in long-term care has also almost exclusively focused on explicit ageism, although a series of recent studies carried out in Canada (Lagace et al. 2011, 2012) on communication patterns between older adults and their caregivers in residential environments had uncovered that ageist language and attitudes are often employed by caregivers.

\subsection{Methodological Approaches in the Study of Ageism}

From our review of the literature, it is immediately apparent that ageism in health care is prevalent but immensely vague as a concept. It is important to consider the balance between older patients' experiences demands, real needs and ethical considerations when analyzing contexts, settings and case studies. This renders measurement even more difficult to achieve. Similarly, in long-term care, Sao Jose and Amado (2017) argue that despite the fact that ageism is "pervasive", it is difficult to define, identify, measure and most important of all to fight. Indeed, they call for research strategies that are capable of detecting, measuring and understanding the multidimensionality/complexity of ageism.

As should by now be apparent, the empirical literature on ageism in health and long-term care addresses a wide variety of forms and manifestations of ageism in these specific settings, which reflect into the diversity of study designs and tools employed by authors. As measurement is both difficult and essential in this field of research, in this section we turn our attention to methodological aspects. In very broad terms, we can talk of two main categories of studies: (i) those attempting to identify or capture ageism and that avail of qualitative methodological approaches and (ii) those that strive to measure or quantify manifest ageism and that rely on quantitative methodological approaches. Each is further described below, with a view of comparing and contrasting the bodies of research in health and in long-term care. In both fields, mixed methods studies are conspicuously rare. We identified only a couple of studies on ageism in health care (Adams et al. 2006; Arber et al. 2006), and only two contributions in long-term care focused research (Lagace et al. 2011; Taverna et al. 2014). As a consequence, we do not treat them as a separate category. This is an unfortunate gap in existing research, as mixed methods approaches offer researchers the opportunity to triangulate and more convincingly validate findings via different methodologies. 


\subsection{Comparison of Research on Ageism in Health and Long-Term Care}

\subsubsection{Qualitative Approaches}

Qualitative studies of ageism in both health and long-term care rely predominantly on interviews for data collection. Researchers generally choose a semi-structured format for interviews, although structured, open and in-depth interviews are also common, and often complement them with other data collection methods. Focus groups and participant observation are also commonly employed methods, in conjunction with interview based data collection (Makris et al. 2005; Skirbekk and Nortvedt 2014; Billings 2006; Gamliel 2000; Lagace et al. 2011) but also as the principle data collection method (Iliffe et al. 2005). Less prevalent in the empirical literature is the use of document analysis (Petersen and Warburton 2012). While many studies do not specifically identify the data analysis methods employed, thematic analysis, content analysis, discourse analysis and ethnographic analysis are commonly cited by authors.

While studies from both categories stated above have addressed ageism both in health and in long-term care settings, imbalances between the frequencies of application of qualitative versus quantitative approaches are apparent in both fields. Namely, qualitative approaches predominate in research on ageism in long-term care, whereas the vast majority of studies of ageism in health care belong to the second category. A systematic review of the literature on ageism in long-term care (Sao Jose and Amado 2017). reveals that qualitative studies are overrepresented in this field and more than twice as numerous as a quantitative approach. Therefore, the variety of qualitative methods employed is higher in the empirical long-term care literature with respect to that focused on health care.

Interestingly, qualitative studies in long-term care seem to favour the selection of older individuals themselves as study participants (Bodner et al. 2011; Doyle 2014; Lagace et al. 2012), in the slight detriment of care professionals (Band-Winterstein 2013; Billings 2006) and family members (Ayalon 2015; Condelius and Andersson 2015). Conversely, in health care based studies, care professionals are relatively more likely to be the subjects of qualitative studies (Skirbekk and Nortvedt 2014; Iliffe et al. 2005), although older adults are also often interviewed with regard to their in-patient and general care experiences (Koch and Webb 1996; Parke and Chappell 2010). We stress that a majority of qualitative studies focus exclusively on one participant group and fail to acknowledge the perspectives of other key actors. As the results cannot be cross-checked and compared, this lack of triangulation in participant selection can lead to one-sided accounts and paint only partial pictures of the contexts the studies attempt to describe. It is however, worth noting that a lack of diversity in participant selection is a problem that affects more severely the literature on ageism in health care. By comparison, qualitative studies in long-term care more routinely include two or all key stakeholders -i.e. older adults, family members and care professional (Dobbs et al. 2008; Lagace et al. 2011; Roth et al. 2015). 
Concerning similarities between the two fields of research, we note a disproportionate preference for studies based in residential care settings, both in the health care and the long-term care literature. When studying the experience of older adults in the health care system, researchers predominantly select in-patient settings and only rarely interview older adults outside the hospital setting (Makris et al. 2015). Similarly, ageism in long-term care is overwhelmingly studied in residential facilities, be they nursing/care homes, assisted living facilities or retirement communities. Only one study selected participants living in their own homes to analyze their experiences in receiving community based formal care (Doyle 2014). Equally rare are research efforts that span care settings. Most noteworthy, Billings (2006) finds evidence of ageist attitudes and discrimination against older people among professionals in health and social care services, working both in the community and in residential and medical care settings. The lack of diversity in the selection of the study setting is a significant shortcoming of empirical research on ageism in both health and long term care, as it fails to reflect the experiences of a wide majority of older individuals, who reside in the community and whose interaction with care professionals is only episodic. While it is understandable that this bias arises as an expression of convenience in participant selection and data collection, it constitutes one of the most significant remaining gaps in qualitative research on ageism.

\subsubsection{Quantitative Approaches}

While outnumbered by qualitative studies in the literature on ageism in long-term care, quantitative studies represent an overwhelming majority of research contributions on ageism in health care settings in our survey. The preferred data collection method, by a wide margin, is the administration of questionnaire based surveys to a selected population of interest. Common methods of survey administration include telephone-based (Austin et al. 2013; Jerant et al. 2004), mail-based (Kearney et al. 2000; Protiere et al. 2010) and direct distribution to participants (Kydd et al. 2014). Virtually all quantitative studies on ageism in long-term care rely on validated scales of ageism for data collection, while in the literature focused on health care a mix of ad-hoc survey instruments (Bouman and Arcelus 2001; Gunderson et al. 2005) and validated instruments is used (please refer to the next section for an overview of the main scales used to measure ageism). While sample sizes and response rates vary widely, in relation to the specific participant population targeted, numerous studies draw on small samples (less than 100 respondents), pointing to a necessity to replicate and reconfirm these findings in other settings and on larger groups in order to establish to what extent their results are generalizable.

While entirely absent from the long-term care literature, studies with randomized experimental designs eliciting the assessment of care professionals for patient/ case vignettes or video clips are not uncommon in health care focused research (Adams et al. 2006; Arber et al. 2006). Similarly, in the health care setting, studies of ageism are also based on registry data (Cruz-Jentoft et al. 2013), on analysis of 
case documentation and files (Bond et al. 2003; Peake et al. 2003), on auditing of clinical research proposals (Briggs et al. 2012), on the analysis of death certificates (Chambaere et al. 2013) and of hospital and other regional medical databases (Gnavi et al. 2007; Grant et al. 2000; Rudd et al. 2007). Due to the lack of coordinated data collection efforts, among other constraints, such studies are rendered virtually impossible and in fact, lack completely, from the empirical literature on ageism in long-term care. Not surprisingly, the range of data analysis methods employed parallels the diversity of methodological approaches to data collection. The most prevalent forms of statistical analysis used include descriptive statistics, analysis of variance and analysis of covariance techniques, factor analysis and regression analysis, but other approaches, driven by the particularities of the collected data can also be identified.

Quantitative studies of ageism using surveys for data collection are almost exclusively directed at care professionals, rather than care users (i.e. older people) both in health and in long-term care. Studies like Bodner et al.' (2011), using self-completion questionnaires to examine differences in ageist attitudes and perceived quality of life among older persons living in residential facilities and in the community, are exceedingly rare in the literature on long term care and, to the best of our knowledge, no similar studies exist in the health care focused literature. Noticeable is also the lack of quantitative studies on ageism that include family members among participants, both in health and long-term care. It is therefore evident that quantitative research has, to date, failed to recognize and appropriately map all relevant actor groups, leaving the perspective and experiences of relatives and close family circles covered exclusively by qualitative research efforts.

The problem of under-representation of diverse settings in studies of ageism in long-term care described above carries fully to the quantitative research literature. Virtually all studies collect data from only one care setting, overwhelmingly a residential care facility (Dunworth and Kirwan 2012). To the best of our knowledge, only Bodner et al. (2011) use a multi-setting data collection approach including individuals living in the community and in sheltered housing arrangements. In studies focusing on ageism in health care a similar imbalance is evident with regard to the over representation of specialist and high intensity care services, in the detriment of primary care based studies (Adams et al. 2006; Arber et al. 2006; Gunderson et al. 2005). Most commonly, the study focus is further narrowed with reference to a specific disease or pathology: diabetes mellitus (Cruz-Jentoft et al. 2013), arthritis (Austin et al. 2013), cardiovascular disease (Bond et al. 2003), spinal cord injury (Furlan et al. 2009), ischemic heart disease (Gnavi et al. 2007), colorectal cancer (Jerant et al. 2004), psychosis (Mitford et al. 2010), lung cancer (Peake et al. 2003), brain injury (Pedersen and Mehlsen 2011), breast cancer (Protiere et al. 2010), stroke (Rudd et al. 2007). This high degree of fragmentation of research results, by clinical specialty and disease group, raises questions about their transferability and generalizability and renders a comprehensive discussion about ageism in health care extremely difficult. 


\subsection{Specific Measurement Tools: Scales of Ageism}

As already hinted above, the majority of quantitative studies on ageism in health and long term care rely on already established instruments, generally described as scales of ageism. While the present review is not exhaustive, we briefly describe those most widely accepted and most commonly used in the health and long-term care literature, listed here in the chronological order of their development.

The Attitudes Towards Older People Scale proposed by Kogan (1961) is composed by 34 statements in a Likert scale format, with item values ranging between 1 (disagree strongly) to 7 (agree strongly) where higher scores indicate more positive attitudes. An attitude index can be computed as the mean of all 34 items. The Attitudes Towards Older People Scale is a uni-dimensional tool that does not recognize any dimensions or factors. It covers the affective and cognitive, other-directed, explicit, positive and negative components of ageism. This scale has been used both in long-term care based (Natan et al. 2013) and in health care based (Furlan et al. 2009; Gallagher et al. 2006; Kearney et al. 2000; Lui and Wong 2009; Topaz and Doron 2013) quantitative studies.

The Aging Semantic Differential Scale (Rosencranz and McNevin 1969) is a multidimensional tool designed to measure attitudes towards older people. It is organized along three factors: (i) level of effective goal orientation, adaptability and energy output of older people, (ii) level of dependency upon others and personal autonomy and (iii) level of social interaction. The tool consists of 32 polar adjectives (e.g. exciting/dull, progressive/old-fashioned, independent/dependent) in a 7-point Likert scale format, where lower values indicate more positive views. It covers the cognitive, other-directed, explicit positive and negative components of ageism. The Aging Semantic Differential Scale covers exclusively the cognitive component of ageism and the explicit and non self-directed aspects. In the empirical literature on ageism in health and long-term care it has been used, among others, by Gething et al. (2002) and Reyna et al. (2007).

The Facts on Aging Quiz was designed and further developed by Palmore (1977, 1998) as a tool for measuring basic knowledge about old age and aging as well as common misconceptions related to it. The proposed scale is uni-dimensional and consists of 50 statements in a true-false format. While it recognizes both positive and negative components of ageism, it covers only the cognitive, other-directed and the explicit component. Applications to the study of ageism in health care include works by Topaz and Doron (2013) and Gethering and colleagues (2002), while in the long-term care settings it has been used by Wells et al. (2004).

Developed in 1990 by Maryann Fraboni and colleagues, the Fraboni Scale of Ageism (Fraboni et al. 1990) was designed to measure attitudes and prejudices towards older people via 29 statements in a Likert scale format. It recognizes three distinct dimensions/factors: antilocution (referring mainly to stereotypes, positive 
and negative, about older people), discrimination (referring to attitudes, positive and negative, towards social rights and social participation of older people) and avoidance (referring to affective attitudes and behavior, positive and negative, with respect to social contact with older people). The scale covers all three classical components and both the positive and negative aspects of ageism, but it focuses exclusively on explicit and non self-direct variants of ageism. Examples of applications to the study of ageism in health and long-term care include Leung et al. (2011) and respectively Bodner et al. (2011) and Lagace et al. (2011).

The Reactions on Ageing Questionnaire (Gething 1994) is an instrument developed to gauge attitudes toward personal aging, a measure that correlates highly with attitudes towards other older people. The scale comprises 27 items in a 6-point Likert scale format, each represented by a statement on expectations regarding old age and is structured along three dimensions: fear of frailty, tedium in later life and losses in later life. It covers the affective and cognitive, other-directed, explicit, positive and negative components of ageism. Although the instrument was developed and primarily used in Australia, subsequent research confirmed its validity in cross-country studies (Gething et al. 2004). Among the studies using the reactions on Ageing Questionnaire, we note Gething et al. (2002), Wells et al. (2004) and Williams et al. (2007).

It is worth noting that all the scales presented above are not specific to health and long-term care research and are broad enough in their scope to be applicable to the analysis of ageism in various other research fields. In fact, the classic scales of ageism have been applied widely in fields as diverse as marketing, media, educational studies, business and organizational theory. This lack of context-specificity can be seen as a limitation, as respondents are requested to think about older people in general and not about older people receiving health and long-term care when answering these scales. Results might differ if the instruments were contextualized.

\subsection{Current Advantages and Shortcomings in Research on Ageism in Health and Long-Term Care}

The empirical literature on ageism in health and long-term care, as it emerges from our analysis of conceptualizations and methodological approaches, is very broad in its scope and touches on a wide range of topics. Although not represented with the same frequency, in depth analyses of ageist attitudes, prejudices and behaviors have been carried out both in long-term care and in health care settings, in a variety of contexts. We note however, a propensity for studies overwhelmingly representing Western cultures. It is therefore, of great importance that the breadth of the field continues to develop in future years, and that further studies are carried out in other geographical areas and in more varied cultural contexts. 
Such expectations do not appear overly optimistic, in light of the considerable development of the field in the last decade. While ageism has been recognized and discussed in the scientific literature for over 50 years, our review has uncovered a proliferation of empirical studies of ageism in health and long-term care over the last 10 years. This is especially true for long-term care based research, where a systematic review of the literature on ageism (Sao Jose and Amado 2017) uncovered that all selected studies were published after the year 2000, more than half of which had appeared between 2011 and 2015. Increased research interest in ageism in health and long-term care no doubt reflects growing awareness on the side of policy makers and the general public of the relevance of the phenomenon in these specific settings. At the same time as more research results become available and are disseminated issues related to ageism are better and more widely understood and hopefully, more easily addressed at the individual, organizational and institutional levels.

On the backdrop of this rapid and positive progression, a series of remaining gaps need to be acknowledged. As a result of persistent theoretical fragmentation and the co-existence of complementary but not entirely over-lapping definitions of the ageism concept, the empirical literature does not reflect the complexities of theoretical thinking on the topic. The mobilization of theories specifically focused on ageism is rare. Furthermore, when mapped against the most comprehensive conceptualization of ageism (Iversen et al. 2009; Sao Jose and Amado 2017), empirical results cluster around few components while entirely failing to acknowledge more refined aspects of ageism. The variants of ageism related to self-directed and to implicit ageism are particularly under-covered.

In a similar vein, we argue the field must strive towards higher complexity and flexibility in data collection and methodological approaches. Mixed methods studies that can integrate insights from both qualitative and quantitative data are all but lacking in the literature.

Finally, while considerable progress is being made in the development of reliable and validated measurement tools, we call attention to persistent shortcomings in the available instruments. Studies often rely on overly general terms and imprecise tools that use abstract terminology. A case in point is the pervasive use of the syntagma "older people" without any qualification on what is to be considered old. Reliance on such homogenizing expressions can mask the considerable diversity characteristic of older populations, confounding the obtained results.

\subsection{Recommendations for Future Research}

Based on the evidence we surveyed in our analysis and building on the gaps and shortcomings identified above, we propose a series of recommendations for future research. We believe development in these areas can help push the field forward and a coordinated research effort to address them is timely and would prove most fruitful. 
As our analysis uncovered a common weakness in underpinning empirical research into theoretical thinking, we recommend that existing theories of ageism should be mobilized more frequently. Such theories can prove extremely helpful for the formulation of research questions but also for intervention and study design and the interpretation of findings.

In fact, a stronger theoretical grounding, that recognizes the inherent complexities of the phenomenon of ageism should go hand in hand with the application of a more comprehensive and ideally, unified definition of ageism that can reflect the multiplicity and complexity of its manifestations. For example, by applying a comprehensive definition of ageism, we uncovered a gap in empirical research and strongly recommend the development of tools and research strategies to measure and assess self-directed ageism and implicit ageism. As long as this is not done, we will continue to have an incomplete picture of the prevalence of ageism in healthcare and long-term care. Furthermore, a unified definition would allow for the comparison of results between studies and across fields, enhancing the validity of the evidence.

Turning to the methodological aspects of research on ageism, we believe future studies should more frequently employ mixed research methods. By drawing on both quantitative and qualitative methodologies, studies can gain both in breadth and depth of understanding, while safeguarding against the shortcoming inherent in using each approach in isolation. Triangulation between data sources and methods can greatly improve the accuracy and reliability of research results and shed light on the finer aspects of the phenomenon of ageism. Furthermore, researchers should strive to enhance triangulation also with respect to participant selection (i.e. include staff members, as well as older people and family members as study subjects) and study setting (i.e. including non-residential settings in the research design) and ensure that all relevant perspectives and the whole gamut of situations and living conditions confronted by older people today are well represented in academic research in health care and long term care.

The quality of available evidence is also likely to improve if future research would rely on a combination of self-reporting techniques with non-self-reporting techniques, such as, participant observation and experimental designs, by helping minimize the impact of reporting biases. Similarly, the adaptation of an existing tool to the specificities of the health and long-term care contexts could help to improve accuracy. We recommend specifically that efforts should be directed to the development of scales and tools that are designed for and sensitive to idiosyncrasies in the care setting. A welcomed improvement on existing scales would also be the elimination of labels such as "old", "elderly", etc. As such scales should also be able to capture "subtyping ageism", a better strategy would be to formulate questions with reference to specific age groups (e.g. 65-75) rather than homogenizing labels.

In conclusion, we wish to acknowledge the great strides that research on ageism in health and long-term care has made over the last decades. This chapter aimed to summarize the wealth of knowledge already existing in the field as well as to provide 
more clarity into the conceptualization and measurement/assessment of ageism in healthcare and long-term care. In so doing, we uncovered great achievements but also "blind spots" in the literature and have, hopefully, charted the way ahead, in an attempt to support researchers, policy makers and practitioners alike in their efforts to address ageism in a variety of contexts.

\section{References}

Adams, A., Buckingham, C. D., Arber, S., McKinlay, J. B., Marceau, L., \& Link, C. (2006). The influence of patient's age on clinical decision-making about coronary heart disease in the USA and the UK. Ageing and Society, 26(02), 303-321.

Ajzen, I. (2005). Attitudes, Personality, and Behavior. New York: McGraw-Hill Education (UK).

American Diabetes Association. (2015). Standards of medical care in diabetes - 2015 abridged for primary care providers. Clinical Diabetes, 33(2), 97-111.

Aminzadeh, F., \& Dalziel, W. B. (2002). Older adults in the emergency department: A systematic review of patterns of use, adverse outcomes, and effectiveness of interventions. Annals of Emergency Medicine, 39(3), 238-247.

Arber, S., McKinlay, J., Adams, A., Marceau, L., Link, C., \& O’Donnell, A. (2006). Patient characteristics and inequalities in doctors' diagnostic and management strategies relating to CHD: A video-simulation experiment. Social Science \& Medicine, 62(1), 103-115.

Austin, S., Qu, H., \& Shewchuk, R. M. (2013). Age bias in physicians' recommendations for physical activity: A behavioral model of health care utilization for adults with arthritis. Journal of Physical Activity \& Health, 10(2), 222-231.

Ayalon, L. (2015). Perceptions of old age and aging in the continuing care retirement community. International Psychogeriatrics, 27(4), 611-6620.

Band-Winterstein, T. (2013). Health care provision for older persons: the interplay between ageism and elder neglect. Journal of Applied Gerontology, 34, 1-15. https://doi. org/10.1177/0733464812475308.

Band-Winterstein, T. (2015). Health care provision for older persons: The interplay between ageism and elder neglect. Journal of Applied Gerontology, 34(3), NP113-NP127.

Billings, J. (2006). Staff perceptions of ageist practice in the clinical setting: Practice development project. Quality in Ageing and Older Adults, 7(2), 33-45.

Bodner, E., Cohen-Fridel, S., \& Yaretzky, A. (2011). Sheltered housing or community dwelling: Quality of life and ageism among elderly people. International Psychogeriatrics, 23(8), 1197-1204.

Bond, M., Bowling, A., McKee, D., Kennelly, M., Banning, A. P., Dudley, N., Elder, A., \& Martin, A. (2003). Does ageism affect the management of ischaemic heart disease? Journal of Health Services Research \& Policy, 8(1), 40.

Boockvar, K., Fishman, E., Kyriacou, C. K., Monias, A., Gavi, S., \& Cortes, T. (2004). Adverse events due to discontinuations in drug use and dose changes in patients transferred between acute and long-term care facilities. Archives of Internal Medicine, 164(5), 545-550.

Bouman, W. P., \& Arcelus, J. (2001). Are psychiatrists guilty of 'ageism' when it comes to taking a sexual history? International Journal of Geriatric Psychiatry, 16(1), $27-31$.

Briggs, R., Robinson, S., \& O’Neill, D. (2012). Ageism and clinical research. Irish Medical Journal, 105(9), 311-312.

Butler, R. N. (1969). Age-ism: Another form of bigotry. The Gerontologist, 9, 243-246.

Butler, R. N. (1975). Why survive? Being old in America. New York: Harper and Row.

Butler, R., \& Lewis, M. (1973). Aging and mental health. St. Louis: C. V. Mosby Co.

Bytheway, B., \& Johnson, J. (2001). An evaluation of the use of diaries in a study of medication in later life. Internaional Journal of Social Research Methodology, 4(3), 183-204. 
Chambaere, K., Rietjens, J. A., Smets, T., Bilsen, J., Deschepper, R., Pasman, H. R. W., \& Deliens, L. (2012). Age-based disparities in end-of-life decisions in Belgium: A population-based death certificate survey. BMC Public Health, 12(1), 1.

Chambaere, K., Rietjens, J. A., Cohen, J., Pardon, K., Deschepper, R., Pasman, H. R. W., \& Deliens, L. (2013). Is educational attainment related to end-of-life decision-making? A large post-mortem survey in Belgium. BMC Public Health, 13(1), 1055.

Chrisler, J. C., Barney, A., \& Palatino, B. (2016). Ageism can be hazardous to women's health: Ageism, sexism, and stereotypes of older women in the healthcare system. Journal of Social Issues, 72(1), 86-104.

Cohen, A., Assyag, P., \& Boutron, I. (2014). Regarding the acute care of the elderly model. JAMA, 174(1), 40-48.

Coleman, E. A. (2003). Falling through the cracks: Challenges and opportunities for improving transitional care for persons with continuous complex care needs. Journal of the American Geriatrics Society, 51(4), 549-555.

Condelius, A., \& Andersson, M. (2015). Exploring access to care among older people in the last phase of life using the behavioural model of health services use: A qualitative study from the perspective of the next of kin of older persons who had died in a nursing home. BMC Geriatrics, 15, 138.

Cruz-Jentoft, A. J., Carpena-Ruiz, M., Montero-Errasquín, B., Sánchez-Castellano, C., \& SánchezGarcía, E. (2013). Exclusion of older adults from ongoing clinical trials about type 2 diabetes mellitus. Journal of the American Geriatrics Society, 61(5), 734-738.

Cuddy, A. J., Norton, M. I., \& Fiske, S. T. (2005). This old stereotype: The pervasiveness and persistence of the elderly stereotype. Journal of Social Issues, 61(2), 267-285.

Dionigi, R. A. (2015). Stereotypes of aging: Their effects on the health of older adults. Journal of Geriatrics, 2015, 1-9.

Dobbs, D., Eckert, J. K., et al. (2008). An ethnographic study of stigma and ageism in residential care or assisted living. The Gerontologist, 48(4), 517-526.

Doyle, S. (2014). The impact of power differentials on the care experiences of older people. Journal of Elder Abuse \& Neglect, 26(3), 319-332.

Dunworth, M., \& Kirwan, P. (2012). Do nurses and social workers have different values? An exploratory study of the care for older people. Journal of Interprofessional Care, Early Online: $1-6$.

Fraboni, M., Saltstone, R., \& Hughes, S. (1990). The Fraboni scale of ageism (FSA): An attempt at a more precise measure of ageism. Canadian Journal on Aging, 9(1), 55-56.

Fried, L. P., \& Ferrucci, L. (2016). Etiological role of aging in chronic diseases: From epidemiological evidence to the new geroscience. In Advances in Geroscience (pp. 37-51). Cham: Springer International Publishing.

Furlan, J. C., Craven, B. C., Ritchie, R., Coukos, L., \& Fehlings, M. G. (2009). Attitudes towards the older patients with spinal cord injury among registered nurses: A cross-sectional observational study. Spinal Cord, 47(9), 674-680.

Gallagher, S., Bennett, K. M., \& Halford, J. C. (2006). A comparison of acute and long-term health-care personnel's attitudes towards older adults. International Journal of Nursing Practice, 12(5), 273-279.

Gamliel, T. (2000). The lobby as an arena in the confrontation between acceptance and denial of old age. Journal of Aging Studies, 14(3), 251-271.

Gatz, M., \& Pearson, C. G. (1988). Ageism revised and the provision of psychological services. American Psychologist, 43(3), 184.

Gething, L. (1994). Health professionals' attitudes towards ageing and older people: Preliminary report of the reactions to ageing questionnaire. Australian Journal on Ageing, 13(2), 77-81.

Gething, L., Fethney, J., McKee, K., Goff, M., Churchward, M., \& Matthews, S. (2002). Knowledge, stereotyping and attitudes towards self ageing. Australasian Journal on Ageing, 21, 74-79.

Gething, L., Fethney, J., McKee, K., Persson, L. O., Goff, M., Churchward, M., Matthews, S., Halvarsson, M., \& Johannsson, I. (2004). Validation of the reactions to ageing questionnaire: 
Assessing similarities across several countries. Journal of Gerontological Nursing, 30(9), 47-54.

Gnavi, R., Migliardi, A., Demaria, M., Petrelli, A., Caprioglio, A., \& Costa, G. (2007). Statins prescribing for the secondary prevention of ischaemic heart disease in Torino, Italy. A case of ageism and social inequalities. The European Journal of Public Health, 17(5), 492-496.

Grant, P. T., Henry, J. M., \& McNaughton, G. W. (2000). The management of elderly blunt trauma victims in Scotland: Evidence of ageism? Injury, 31(7), 519-528.

Greenberg, J., Schimel, J., \& Martens, A. (2002). Ageism: Denying the face of the future. In T. D. Nelson (Ed.). Cambridge, MA: MIT Press.

Gunderson, A., Tomkowiak, J., Menachemi, N., \& Brooks, R. (2005). Rural physicians' attitudes toward the elderly: Evidence of ageism? Quality Management in Healthcare, 14(3), 167-176.

Hawkes, N. (2016). Sixty seconds on... bed blockers. BMJ, 352, i935.

Holroyd, A., Dahlke, S., Fehr, C., Jung, P., \& Hunter, A. (2009). Attitudes toward aging: Implications for a caring profession. Journal of Nursing Education, 48(7), 374-380.

Hubbard, R. E., Lyons, R. A., Woodhouse, K. W., Hillier, S. L., Wareham, K., Ferguson, B., \& Major, E. (2003). Absence of ageism in access to critical care: A cross-sectional study. Age and Ageing, 32(4), 382-387.

Hunold, K. M., Pereira, G. F., Jones, C. W., Isaacs, C. G., Braz, V. A., Gadi, S., \& Platts-Mills, T. F. (2016). Priorities of care among older adults in the emergency department: A cross-sectional study. Academic Emergency Medicine, 23, 362-365.

Iliffe, S., De Lepeleire, J., Van Hout, H., Kenny, G., Lewis, A., Vernooij-Dassen, M. J. F. J., \& The Diadem Group. (2005). Understanding obstacles to the recognition of and response to dementia in different European countries: A modified focus group approach using multinational, multi-disciplinary expert groups. Aging \& Mental Health, 9(1), 1-6.

Iversen, T. N., Larsen, L., \& Solem, P. E. (2009). A conceptual analysis of ageism. Nordic Psychology, 61(3), 4-22.

Jerant, A. F., Franks, P., Jackson, J. E., \& Doescher, M. P. (2004). Age-related disparities in cancer screening: Analysis of 2001 behavioral risk factor surveillance system data. The Annals of Family Medicine, 2(5), 481-487.

Kearney, N., Miller, M., Paul, J., \& Smith, K. (2000). Oncology healthcare professionals' attitudes toward elderly people. Annals of Oncology, 11(5), 599-601.

Koch, T., \& Webb, C. (1996). The biomedical construction of ageing: Implications for nursing care of older people. Journal of Advanced Nursing, 23(5), 954-958.

Koch, S., Hunter, P., \& Nair, K. (2009). Older people in acute care. Older people: Issues and innovafions in care (3rd ed.pp. 153-167). Sydney: Churchill Livingstone.

Kogan, N. (1961). Attitudes towards old people: The development of a scale and examination of correlates. Journal of Abnormal and Social Psychology, 62, 44-54.

Kydd, A., Touhy, T., Newman, D., Fagerberg, I., \& Engstrom, G. (2014). Attitudes towards caring for older people in Scotland, Sweden and the United States: Angela.

Lagacé, M., Medouar, F., Loock, J., \& Davignon, A. (2011). À mots couverts: le regard des aînés et des soignants sur la communication quotidienne et ses manifestations d'âgisme implicite. Canadian Journal of Aging/La Revue canadienne du vieillissement, 30, 185-196.

Lagacé, M., Tanguay, A., Lavallée, M., et al. (2012). The silent impact of ageist communication in long term care facilities: Elders' perspectives on quality of life and coping strategies. Journal of Aging Studies, 26, 335-342.

Leung, S., LoGiudice, D., Schwarz, J., \& Brand, C. (2011). Hospital doctors' attitudes towards older people. Internal Medicine Journal, 41(4), 308-314.

Levy, B. (2009). Stereotype embodiment a psychosocial approach to aging. Current Directions in Psychological Science, 18(6), 332-336.

Levy, B. R., \& Banaji, M. R. (2002). Implicit ageism. In T. D. Nelson (Ed.), Ageism stereotyping and prejudice against older persons (pp. 49-75). Cambridge, MA: MIT Press. 
Levy, B. R., Slade, M. D., \& Gill, T. M. (2006). Hearing decline predicted by elders' stereotypes. The Journals of Gerontology. Series B, Psychological Sciences and Social Sciences, 61(2), $82-87$.

Lui, N. L., \& Wong, C. H. (2009). Junior doctors' attitudes towards older adults and its correlates in a tertiary-care public hospital. Annals Academy of Medicine Singapore, 38(2), 125.

MacDonald, C., \& Butler, L. (2007, January). Silent no more: Elderly women's stories of living with urinary incontinence in long-term care. Journal of Gerontological Nursing, 14(20), 14-20.

Makris, U. E., Higashi, R. T., Marks, E. G., Fraenkel, L., Sale, J. E., Gill, T. M., \& Reid, M. C. (2015). Ageism, negative attitudes, and competing co-morbidities-why older adults may not seek care for restricting back pain: A qualitative study. BMC Geriatrics, 15(1), 1.

Maxim Topaz, R. N. M. A., \& Israel Issi Doron, L. L. B. (2013). Nurses' attitudes toward older patients in acute care in Israel. Online Journal of Issues in Nursing, 18(1), 61.

Minichiello, V., Browne, J., \& Kendig, H. (2000). Perceptions and consequences of ageism: Views of older people. Ageing and Society, 20(03), 253-278.

Mitford, E., Reay, R., McCabe, K., Paxton, R., \& Turkington, D. (2010). Ageism in first episode psychosis. International Journal of Geriatric Psychiatry, 25(11), 1112-1118.

Moos, R. H. (1979). Social ecological perspectives on health. In G. C. Stone, F. Cohen, \& N. E. Adler (Eds.), Health psychology: A handbook (pp. 523-547). San Francisco: Jossey-Bass.

Natan, M. B., Ataneli, M., Admenko, A., \& Noy, R. H. (2013). Nurse assessment of residents' pain in a long-term care facility. International Nursing Review, 60, 251-257.

Nelson, T. D. (2005). Ageism: Prejudice against our feared future self. Journal of Social Issues, 61(2), 207-221.

Palmore, E. B. (1977). Facts on aging: A short quiz. Gerontologist, 17, 315-320.

Palmore, E. B. (1998). The facts on aging quiz. New York: Springer.

Parke, B., \& Chappell, N. L. (2010). Transactions between older people and the hospital environment: A social ecological analysis. Journal of Aging Studies, 24(2), 115-124.

Peake, M. D., Thompson, S., Lowe, D., \& Pearson, M. G. (2003). Ageism in the management of lung cancer. Age and Ageing, 32(2), 171-177.

Pedersen, A. D., \& Mehlsen, M. (2011). Age-bias in staff appraisals of brain injury service provision? Nordic Psychology, 63(3), 25.

Petersen, M., \& Warburton, J. (2012). Residential complexes in Queensland, Australia: A space of segregation and ageism? Ageing and Society, 32(01), 60-84.

Protière, C., Viens, P., Rousseau, F., \& Moatti, J. P. (2010). Prescribers' attitudes toward elderly breast cancer patients. Discrimination or empathy? Critical Reviews in Oncology/Hematology, $75(2), 138-150$.

Reyna, C., Goodwin, E. J., \& Ferrari, J. R. (2007). Older adult stereotypes among care providers in residential care facilities. Journal of Gerontological Nursing, 33(2), 50-55.

Robb, C., Haley, W. E., Becker, M. A., Polivka, L. A., \& Chwa, H. J. (2003). Attitudes towards mental health care in younger and older adults: Similarities and differences. Aging \& Mental Health, 7(2), 142-152.

Rosencranz, H. A., \& McNevin, T. E. (1969). A factor analysis of attitudes toward the aged. Gerontologist, 9(1), 55-59.

Roth, E. G., Keimig, L., Rubinstein, R. L., Morgan, L., Eckert, J. K., Goldman, S., \& Peeples, A. D. (2012).

Roth, E. G., Eckert, J. K., \& Morgan, L. A. (2015). Stigma and discontinuity in multilevel senior housing's continuum of care. Gerontologist, $00(00), 1-10$.

Rudd, A. G., Hoffman, A., Down, C., Pearson, M., \& Lowe, D. (2007). Access to stroke care in England, Wales and Northern Ireland: The effect of age, gender and weekend admission. Age and Ageing, 36(3), 247-255.

São José, J., \& Amado, C. (2017). On studying ageism in long-term care: A systematic review of the literature. International Psychogeriatrics, 29(3), 373-387.

São José, J., Amado, C., Ilinca, S., Buttigieg, S., \& Taghizadeh Lars-son, A. (2017). Ageism in health care: A systematic review of operational definitions and inductive conceptualizations. The Gerontologist. https://doi.org/10.1093/geront/gnx020 
Scott, V., Votova, K., Scanlan, A., \& Close, J. (2007). Multifactorial and functional mobility assessment tools for fall risk among older adults in community, home-support, long-term and acute care settings. Age and Ageing, 36(2), 130-139.

Skirbekk, H., \& Nortvedt, P. (2014). Inadequate treatment for elderly patients: Professional norms and tight budgets could cause "ageism" in hospitals. Health Care Analysis, 22(2), 192-201.

Solomon, S., Greenberg, J., \& Pyszczynski, T. (1991). A terror management theory of social behavior: The psychological functions of self-esteem and cultural worldviews. Advances in Experimental Social Psychology, 24, 93-159.

Stokols, D. (1992). Establishing and maintaining healthy environments: Toward a social ecology of health promotion. American Psychologist, 47(1), 6.

Taverna, M. V., Nguyen, C., Wright, R., et al. (2014). Iatro-compliance: An unintended consequence of excessive autonomy in long term care facilities. Journal of Dental Hygiene, 88(1), 53-60.

Tinetti, M. E., Esterson, J., Ferris, R., Posner, P., \& Blaum, C. S. (2016). Patient priority-directed decision making and care for older adults with multiple chronic conditions. Clinics in Geriatric Medicine, 32(2), 261-275.

Turner, J. C., \& Reynolds, K. J. (2010). The story of social identity. In T. Postmes \& N. Branscombe (Eds.), Rediscovering social identity: Core sources. New York: Psychology Press.

United Nations, Department of Economic and Social Affairs, Population Division. (2015). World population ageing 2015 (ST/ESA/SER.A/390). http://www.un.org/en/development/desa/population/publications/pdf/ageing/WPA2015_Report.pdf. Accessed 15 Apr 2016.

Wells, Y., Foreman, P., Gething, L., \& Petralia, W. (2004). Nurses' attitudes toward aging and older adults - Examining attitudes and practices among health services providers in Australia. Journal of Gerontological Nursing, 30(9), 5-13.

Williams, B., Anderson, M. C., \& Day, R. (2007). Undergraduate nursing students' knowledge of and attitudes toward aging: Comparison of context-based learning and a traditional program. Journal of Nursing Education, 46(3), 115-120.

Zimmerman, S., Dobbs, D., Roth, E. G., Goldman, S., Peeples, A. D., \& Wallace, B. (2014). Promoting and protecting against stigma in assisted living and nursing homes. Gerontologist, $56,535-547$.

Open Access This chapter is licensed under the terms of the Creative Commons Attribution 4.0 International License (http://creativecommons.org/licenses/by/4.0/), which permits use, sharing, adaptation, distribution and reproduction in any medium or format, as long as you give appropriate credit to the original author(s) and the source, provide a link to the Creative Commons license and indicate if changes were made.

The images or other third party material in this chapter are included in the chapter's Creative Commons license, unless indicated otherwise in a credit line to the material. If material is not included in the chapter's Creative Commons license and your intended use is not permitted by statutory regulation or exceeds the permitted use, you will need to obtain permission directly from the copyright holder.

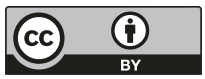

